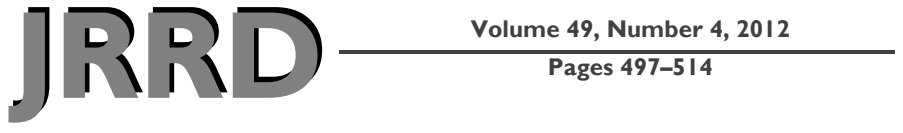

\section{Review of hybrid exoskeletons to restore gait following spinal cord injury}

\author{
Antonio J. del-Ama, Eng MSc; ${ }^{1-2 *}$ Aikaterini D. Koutsou, Eng MSc; ${ }^{2}$ Juan C. Moreno, Eng PhD; $^{2}$ Ana de-los-Reyes, \\ Eng MSc; ${ }^{1}$ Ángel Gil-Agudo, MD, PhD; ${ }^{1}$ José L. Pons, Prof Eng PhD ${ }^{2}$ \\ ${ }^{1}$ Biomechanics and Technical Aids Unit, National Hospital for Spinal Cord Injury, SESCAM, Toledo, Spain; \\ ${ }^{2}$ BioEngineering Group, National Council for Scientific Research, Arganda del Rey, Madrid, Spain
}

\begin{abstract}
Different approaches are available to compensate gait in persons with spinal cord injury, including passive orthoses, functional electrical stimulation (FES), and robotic exoskeletons. However, several drawbacks arise from each specific approach. Orthotic gait is energy-demanding for the user and functionally ineffective. FES uses the muscles as natural actuators to generate gait, providing not only functional but also psychological benefits to the users. However, disadvantages are also related to the early appearance of muscle fatigue and the control of joint trajectories. Robotic exoskeletons that provide joint moment compensation or substitution to the body during walking have been developed in recent years. Significant advances have been achieved, but the technology itself is not mature yet because of many limitations related to both physical and cognitive interaction as well as portability and energy-management issues. Meanwhile, the combination of FES technology and exoskeletons has emerged as a promising approach to both gait compensation and rehabilitation, bringing together technologies, methods, and rehabilitation principles that can overcome the drawbacks of each individual approach. This article presents an overview of hybrid lower-limb exoskeletons, related technologies, and advances in actuation and control systems. Also, we highlight the functional assessment of individuals with spinal cord injury.
\end{abstract}

Key words: exoskeleton, functional electrical stimulation, gait, hybrid control, muscle fatigue, neuroprosthesis, neurorobot, orthosis, rehabilitation, robot control, spinal cord injury, wearable robot.

\section{INTRODUCTION}

Paraplegia resulting from spinal cord injury (SCI) is characterized primarily by the loss of motor and sensory abilities, the severity of which is determined by the level and characteristics of the injury [1]. Among SCI patients, gait impairment constitutes one of the most disabling impairments and may involve the complete loss of voluntary control of the leg muscles. Thus, individuals with paraplegia commonly rely on wheelchairs for their mobility [2].

Recent studies have attempted to identify the most important functions in the SCI population, with a view to enhancing quality of life [3-7]. Although different methods were used in these studies, all identified mobility as one of the main objectives for the injured individuals. Interestingly, several differences between the preferences of patients and those of clinical professionals have been

\footnotetext{
Abbreviations: $6 \mathrm{MWT}=6$-minute walking test, $10 \mathrm{MWT}=10 \mathrm{~m}$ walking test, $\mathrm{AFO}=$ ankle-foot orthosis, ASIA = American Spinal Injury Association, $\mathrm{C}$ = cervical, $\mathrm{CBO}=$ controlled-brake orthosis, $\mathrm{DC}=$ direct current (motor), ESO = energy-storing orthosis, FES = functional electrical stimulation, HAS = hybrid assistive system, HKAFO = hip-knee-ankle-foot orthosis, HyPo = hybrid powered orthosis, KAFO = knee-ankle-foot orthosis, PID = proportional-integral-derivative, $\mathrm{RGO}=$ reciprocating gait orthosis, SCI = spinal cord injury, SFMO = self-fitting modular orthosis, $\mathrm{T}=$ thoracic, WISCI II = Walking Index for Spinal Cord Injury Version 2.

*Address all correspondence to Antonio J. del-Ama, Eng MSc; Biomechanics and Technical Aids Unit, National Hospital for Spinal Cord Injury, SESCAM, Finca la Peraleda s/n, 45071 Toledo, Spain; +34-925247779.

Email: ajdela@sescam.jccm.es

http://dx.doi.org/10.1682/JRRD.2011.03.0043
} 
reported [4]. While mobility was a high priority among patients at all stages of rehabilitation, the expert panel selected independent wheelchair mobility as the most important final goal of rehabilitation, which was attributed to the pressure to discharge patients because of time constraints. However, it is important to highlight that restoring the capacity to walk was identified as the highest priority objective, regardless of the lesion level, time since injury, or age [4].

Different approaches to gait restoration are currently available. While orthotic gait involves both passive and active orthotic approaches, FES-based approaches explore the possibilities of electrical stimulation of the user's muscles. We shall consider these here, as well as alternative hybrid functional electrical stimulation (FES)-based approaches.

\section{Orthotic Gait}

The first system to be introduced clinically for gait compensation was a mechanical structure that locked or limited joint movement during the stance phase of gait, such as the ankle-foot orthosis (AFO), the knee-AFO (KAFO), or the hip-KAFO (HKAFO), depending on the specific joint weakness. The traditional KAFO design was developed in the 1950s to assist ambulatory management after poliomyelitis epidemics [8]. KAFOs or HKAFOs allow swing-through mobility with the use of walkers or crutches. The mobility achieved with these devices is aesthetically poor and requires high metabolic energy expenditure. Indeed, the energetic cost associated with this kind of ambulation is up to 43 percent higher than that of wheelchairs [9], which partially explains the low impact of such orthoses compared with wheelchairs. Some years later, in an effort to develop a less demanding gait, dynamic orthoses that allowed passive hip joint movement were developed: the reciprocating gait orthosis (RGO) [10], the advanced RGO [11], the hip guidance orthosis [12], the ParaWalker [13], and the Walkabout [14]. Gait achieved with these orthotic systems was improved with respect to the rigid HKAFOs [15], although problems with slow walking and high energy cost have been identified as reasons for discontinuing their use [16-18].

Recent decades have seen a growing interest in the development of active orthoses capable of adding and controlling power at the joints. The first such example dates from the 1970s, when Vukobratovic et al. developed an active orthosis comprised of actuators at hip, knee, and ankle joints to assist movement in the sagittal plane [19]. Since then, many active exoskeletons have been developed for gait restoration, with considerable variation in actuator and sensing technologies, and control strategies. However, as with passive orthoses, exoskeletons for gait restoration are not yet a viable means of providing effective gait compensation because of the many limitations that are still to be overcome [20-23]. Although new promising exoskeletons are in clinical trials [24-25], further studies should be performed in the clinical setting to understand whether the limitations already identified in previous studies are addressed.

\section{Functional Electrical Stimulation-Aided Gait}

Electrical stimulation of muscles has been widely explored as a means of gait compensation in subjects with SCI, whereby the muscles of the user are stimulated by previously configured electrical impulses to generate joint movement [26]. Since the movement is achieved via the users own muscles, FES-aided gait provides a high degree of autonomy of use [27].

The use of FES technology, or FES-assisted systems, for human muscle activation dates back to the early 1960s. The first applications of FES-assisted systems in paraplegia used a transcutaneous FES system to stimulate the quadriceps and gluteus to induce gait patterns [28] and to study the correction of drop-foot [29]. The FES system developed by Kralj et al. in 1983 proposed closed-loop stimulation of the quadriceps muscle group and the peroneal nerves to achieve paraplegic gait [30]. The last two decades have seen the development of several FES systems based on the designs of Kantrowitz and Liberson [31-38], and the recent advances in FES technology offer the possibility of achieving more complex and efficient stimulation. The control of FES systems has been improved through multichannel stimulators that can be combined with percutaneous and implanted electrodes. This approach leads to improved muscle selectivity because each muscle uses a different electrode.

The use of FES also imposes challenges that limit its widespread use for gait compensation. The early onset of muscle fatigue precludes long periods of stimulation, limiting walking distance. The fine control of joint trajectories by FES remains problematic because of the nature of the musculoskeletal system. These drawbacks have limited the widespread application of FES for gait compensation among SCI patients [39]. 


\section{Hybrid Approaches}

Among the interventions available, several technical limitations prevent satisfactory gait compensation following SCI. Of the approaches just described, the combination of FES technology and exoskeletons has emerged as a promising approach to achieve both gait compensation and rehabilitation, bringing together technologies, methods, and rehabilitation principles that can overcome the drawbacks of each individual approach.

There have been many attempts to improve gait performance and decrease energy expenditure by combining FES with different types of passive or reciprocating orthoses. However, the inclusion of FES in such approaches provides little improvement in energy cost and gait velocity. Specifically, a recent review concluded that limited evidence supports the uses of both bracing and FES for additional functional ambulation benefit in paraplegic patients with complete SCI [40]. Thus, the high energy cost associated with these hybrid bracing systems appears to be the main drawback [41-44].

The addition of FES to exoskeleton systems takes advantage of the muscle power generated to reduce the energy demand of the exoskeleton, thereby requiring less powerful joint actuators, which would result in a lighter system. Moreover, such hybrid exoskeletons should promote more effective neural plasticity than other standard practices like treadmill training, because of the intensive, community-based gait practice involved. This gait practice occurs during daily training, and thus, increased user participation is promoted during walking training. While FES-induced gait has several benefits, mainly related to muscle strength and cardiorespiratory fitness [40,45-47], it is not so effective in gait restoration $[40,48]$ and is limited to a therapeutic environment [39]. Furthermore, FES can induce muscle fatigue, leading to interruptions in training. Improved management of muscle stimulation is therefore crucial to the development of successful hybrid exoskeletons that can be used for longer periods of time.

The aim of this article is to review the state of the art of hybrid exoskeletons. For the purpose of this article, we define "hybrid exoskeletons" as systems that aim to compensate and/or rehabilitate gait in activities of daily living by means of delivering and controlling power to the lowerlimb joints, in which the net joint power results from the combination of muscle activation with FES and electromechanical actuation at the joint level. This review identifies the main challenges in designing and developing hybrid lower-limb exoskeletons and highlights the most relevant features that must be considered for the functional assessment of individuals with SCI.

\section{METHODS}

A search of the Medline, Science Direct, IEEE Xplore digital library, and Google Scholar databases was performed using the following combinations of terms:

- (Hybrid AND Exoskeleton) within title and abstract.

- (Hybrid AND Orthosis) within title and abstract.

- ((Functional Electrical Stimulation OR FES) AND gait) within title and abstract.

- ((Functional Electrical Stimulation OR FES) AND exoskeleton) within title and abstract.

- (Gait AND robot) within title and abstract.

After rejecting duplicate articles, we identified 497 articles. The title and key words of these articles were initially inspected, which resulted in the rejection of 79.3 percent (394) as inappropriate. After carefully reading the abstract of the remaining 103 articles, we discarded 67 percent (69). No additional relevant articles were found by forward and reverse citation. As a result, the final database contained 34 articles that comprised the main information source of this article (Table).

\section{RESULTS}

\section{Hybrid Exoskeletons}

The concept of hybrid exoskeletons was first introduced in 1978 [49], though actual physical construction and preliminary results were not reported until 1989 [50]. Different systems have since been proposed, with diverse actuation and control principles. However, two main categories can be distinguished in relation to the exoskeleton joint actuation principle: (1) power dissipation at joint (braking or clutching) and (2) active joint actuators. We have adhered to these criteria in our review of hybrid exoskeletons.

\section{Hybrid Exoskeletons Controlled by Joint Brakes}

Attaching controllable brakes to a passive gait orthosis allows the use of FES as a power source to generate gait, controlling joint movements by closed-loop control of joint trajectory. This poses a solution to the problem of joint trajectory control generated by FES [51]. In addition, placing joint brakes on the orthosis obviates the 
JRRD, Volume 49, Number 4, 2012

Table.

Hybrid exoskeletons reviewed.

\begin{tabular}{|c|c|c|c|c|}
\hline System & Exoskeleton & FES & Clinical Evaluation & Drawback \\
\hline $\begin{array}{l}\text { Variable Hip Constraint } \\
\text { Mechanism [1-2] }\end{array}$ & $\begin{array}{l}\text { Hip: hydraulic. } \\
\text { Knee \& ankle: brake. }\end{array}$ & $\begin{array}{l}16 \text { channels. } \\
\text { Open loop. }\end{array}$ & 1 subject [2]: complete T7. & $\begin{array}{l}\text { Weight. } \\
\text { Cannot add power to joints. } \\
\text { FES parameters preprogrammed. }\end{array}$ \\
\hline $\begin{array}{l}\text { Controlled-Brake Orthosis } \\
\text { [3-4] }\end{array}$ & $\begin{array}{l}\text { Hip \& knee: brake. } \\
\text { Ankle: elastic. }\end{array}$ & $\begin{array}{l}4 \text { channels. } \\
\text { Closed loop: muscular fatigue }\end{array}$ & $\begin{array}{l}1 \text { subject [4]: complete T6. } \\
4 \text { subjects [5]: } 3 \text { complete }\end{array}$ & $\begin{array}{l}\text { Cannot add power to joints. } \\
\text { Use of withdrawal reflex. }\end{array}$ \\
\hline
\end{tabular}

monitoring. $\quad$ T6-T7, 1 incomplete T8.

Peroneal nerve stimulation for hip \& knee flexion.

\begin{tabular}{|c|c|c|c|c|}
\hline $\begin{array}{l}\text { Joint-Coupled Orthosis } \\
\text { [6-7] }\end{array}$ & $\begin{array}{l}\text { Hip \& knee: brake \& elastic } \\
\text { \& mechanical coupling. }\end{array}$ & $\begin{array}{l}2 \text { channels. } \\
\text { Open loop. } \\
\text { Energy storage from muscle } \\
\text { stimulation. }\end{array}$ & Not evaluated. & $\begin{array}{l}\text { Cannot add power to joints. } \\
\text { FES parameters preprogrammed. }\end{array}$ \\
\hline $\begin{array}{l}\text { Spring-Brake Orthosis } \\
\text { [8-9] }\end{array}$ & $\begin{array}{l}\text { Hip \& knee: brake \& elastic } \\
\text { \& mechanical coupling. }\end{array}$ & $\begin{array}{l}2 \text { channels. } \\
\text { Closed loop. } \\
\text { Energy storage from muscle } \\
\text { stimulation. }\end{array}$ & Not evaluated. & Cannot add power to joints. \\
\hline $\begin{array}{l}\text { Energy Storing Orthosis } \\
\text { (ESO) [10-12] }\end{array}$ & $\begin{array}{l}\text { Hip \& knee: brake \& elastic } \\
\text { \& pneumatic coupling. }\end{array}$ & $\begin{array}{l}2 \text { channels. } \\
\text { Open loop. } \\
\text { Energy storage from muscle } \\
\text { stimulation. }\end{array}$ & Not evaluated. & $\begin{array}{l}\text { Cannot add power to joints. } \\
\text { FES parameters preprogrammed. }\end{array}$ \\
\hline $\begin{array}{l}\text { Hybrid Assistive System } \\
\text { (HAS) [13] }\end{array}$ & $\begin{array}{l}\text { Knee: DC motor \& brake. } \\
\text { Ankle: elastic. }\end{array}$ & $\begin{array}{l}6 \text { channels. } \\
\text { Open loop. } \\
\text { Peroneal nerve stimulation for } \\
\text { hip \& knee flexion. }\end{array}$ & $\begin{array}{l}1 \text { subject [13]: incomplete } \\
\text { C5-C6. }\end{array}$ & $\begin{array}{l}\text { No control of FES. } \\
\text { Use of withdrawal reflex. } \\
\text { FES parameters preprogrammed. } \\
\text { Position-controlled joints. }\end{array}$ \\
\hline $\begin{array}{l}\text { Hybrid Powered Orthosis } \\
\text { (HyPO) [14-15] }\end{array}$ & Hip \& knee: DC motor. & $\begin{array}{l}2 \text { channels. } \\
\text { Open loop. }\end{array}$ & Not evaluated. & $\begin{array}{l}\text { FES parameters preprogrammed. } \\
\text { Joints only controlled by position. }\end{array}$ \\
\hline WalkTrainer [16] & $\begin{array}{l}\text { Pelvis, hip, knee, \& ankle: } \\
\text { DC motor. }\end{array}$ & $\begin{array}{l}20 \text { channels. } \\
\text { Closed loop: minimization of } \\
\text { interaction forces. }\end{array}$ & $\begin{array}{l}6 \text { subjects [16]: } 2 \text { complete } \\
\text { paraplegia, } 4 \text { incomplete } \\
\text { paraplegia. }\end{array}$ & $\begin{array}{l}\text { Too bulky: only for clinic use. } \\
\text { No muscular fatigue monitoring. }\end{array}$ \\
\hline
\end{tabular}

1. To CS, Kobetic R, Schnellenberger JR, Audu ML, Triolo RJ. Design of a variable constraint hip mechanism for a hybrid neuroprosthesis to restore gait after spinal cord injury. IEEE/ASME Trans Mechatron. 2008;13(2):197-205.

2. Kobetic R, To CS, Schnellenberger JR, Audu ML, Bulea TC, Gaudio R, Pinault G, Tashman S, Triolo RJ. Development of hybrid orthosis for standing, walking, and stair climbing after spinal cord injury. J Rehabil Res Dev. 2009;46(3):447-62.

3. Durfee WK, Goldfarb M. Design of a controlled-brake orthosis for regulating FES-aided gait. Proceedings of the Annual International Conference of the IEEE Engineering in Medicine and Biology Society, vol. 14; 1992 Oct 29-Nov 1; Paris, France. Piscataway (NJ): IEEE; 1992. p. $1337-38$.

4. Goldfarb M, Durfee WK. Design of a controlled-brake orthosis for FES-aided gait. IEEE Trans Rehabil Eng. 1996;4(1):13-24.

5. Goldfarb M, Korkowski K, Harrold B, Durfee W. Preliminary evaluation of a controlled-brake orthosis for FES-aided gait. IEEE Trans Neural Syst Rehabil Eng. 2003;11(3):241-48.

6. Farris RJ, Quintero HA, Withrow TJ, Goldfarb M. Design of a joint-coupled orthosis for FES-aided gait. 2009 IEEE 11th International Conference on Rehabilitation Robotics; 2009 Jun 23-26; Kyoto, Japan. Piscataway (NJ): IEEE; 2009. p. 246-52.

7. Farris RJ, Quintero HA, Withrow TJ, Goldfarb M. Design and simulation of a joint-coupled orthosis for regulating FES-aided gait. 2009 IEEE 11th International Conference on Rehabilitation Robotics; 2009 Jun 23-26; Kyoto, Japan. Piscataway (NJ): IEEE; 2009. p. $1916-22$.

8. Gharooni S, Tokhi MO, Heller B. The use of elastic element in a hybrid orthosis for swing phase generation in orthotic gait. Proceedings of the Annual Conference of the International Functional Electrical Stimulation Society; 2000; Aalborg, Denmark.

9. Gharooni S, Heller B, Tokhi MO. A new hybrid spring brake orthosis for controlling hip and knee flexion in the swing phase. IEEE Trans Neural Syst Rehabil Eng. 2001;9(1):106-107.

10. Durfee WK, Rivard A. Design and simulation of a pneumatic, stored-energy, hybrid orthosis for gait restoration. J Biomech Eng. 2005;127(6):1014-19.

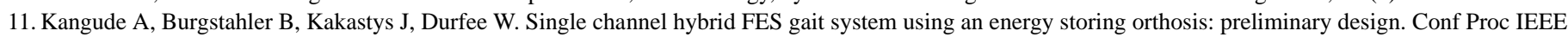
Eng Med Biol Soc. 2009;2009:6798-801.

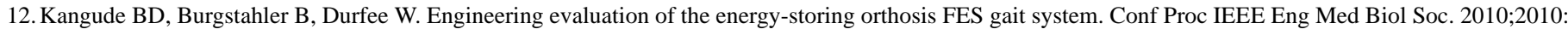
5927-30.

13. Popovic D, Tomovi R, Schwirtlich L. Hybrid assistive system-the motor neuroprosthesis. IEEE Trans Biomed Eng. 1989;36(7):729-37.

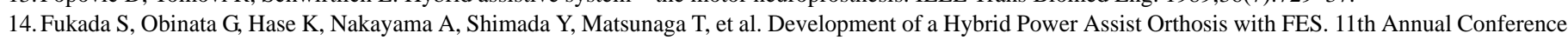
of the International Functional Electrical Stimulation Society; 2006 Sep 12-15; Sendai, Japan.

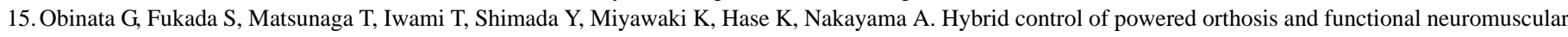
stimulation for restoring gait. Conf Proc IEEE Eng Med Biol Soc. 2007;2007:4879-82.

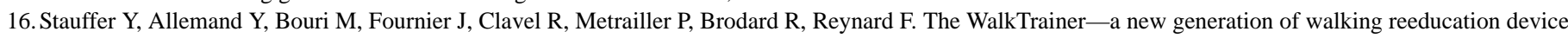
combining orthoses and muscle stimulation. IEEE Trans Neural Syst Rehabil Eng. 2009;17(1):38-45.

$\mathrm{C}=$ cervical, $\mathrm{DC}=$ direct current, FES $=$ functional electrical stimulation, $\mathrm{T}=$ thoracic. 
need for stimulation of muscles during stance phases of gait, which is very exhausting for the muscles under stimulation.

\section{Variable Hip Constraint Mechanism}

RGOs are HKAFOs in which the hips are coupled by a mechanical linkage so that hip flexion provides coupled contralateral hip extension while keeping the knee and ankle fixed [52]. As a result, walking requires considerable side-to-side movement so that the foot can clear the floor and the 1:1 coupling ratio limits step length. To improve performance with this system, some modifications have been tested, including unlocking the knee joint during swing to improve foot clearance [35] and increasing the hip coupling ratio to 2:1 to increase step length and reduce energy cost [53]. Accordingly, a hybrid neuroprosthetic system has been developed in which the hip and knee joints are driven by spring clutches that either release or block the joints [54]. The FES system is comprised of 26 intramuscular electrodes to control the trunk, hip, knee, and ankle joints. While more flexible step length and improved walking speeds were achieved, the posture and stability of the user was compromised as a result of the hip actuation principle (spring clutch) and the onset of muscle fatigue in hip extensors.

To overcome the limitations related to the hip mechanism, newer designs include a variable hip coupling mechanism in which the coupling ratio between the hip joints could be modified by means of a controllable hydraulic system (Figure 1) [55-57]. In this apparatus, hydraulic cylinders fixed by rack-and-pinion transmission produce hip actuation. The losses due to friction in the mechanism were quantified as 7 percent of the hip flexor muscle power required to overcome the passive resistance of the actuator [55,57]. However, the amount of torque required to move the hip mechanism was later reported to be 10 percent of the hip torque generated during FES-driven gait [56]. The control of the hydraulic circuit avoids bilateral hip flexion while providing trunk and hip stability and free or coupled hip movement during the swing phase of gait. This allows the user to modify his or her step length without the intervention of the system.

This hybrid neuroprosthesis also features a solenoidactivated spring clutch mechanism for the knee joint, blocking flexion of the knee during stance while allowing some degree of knee flexion during swing. The ankle is driven by a purely elastic element. The FES system

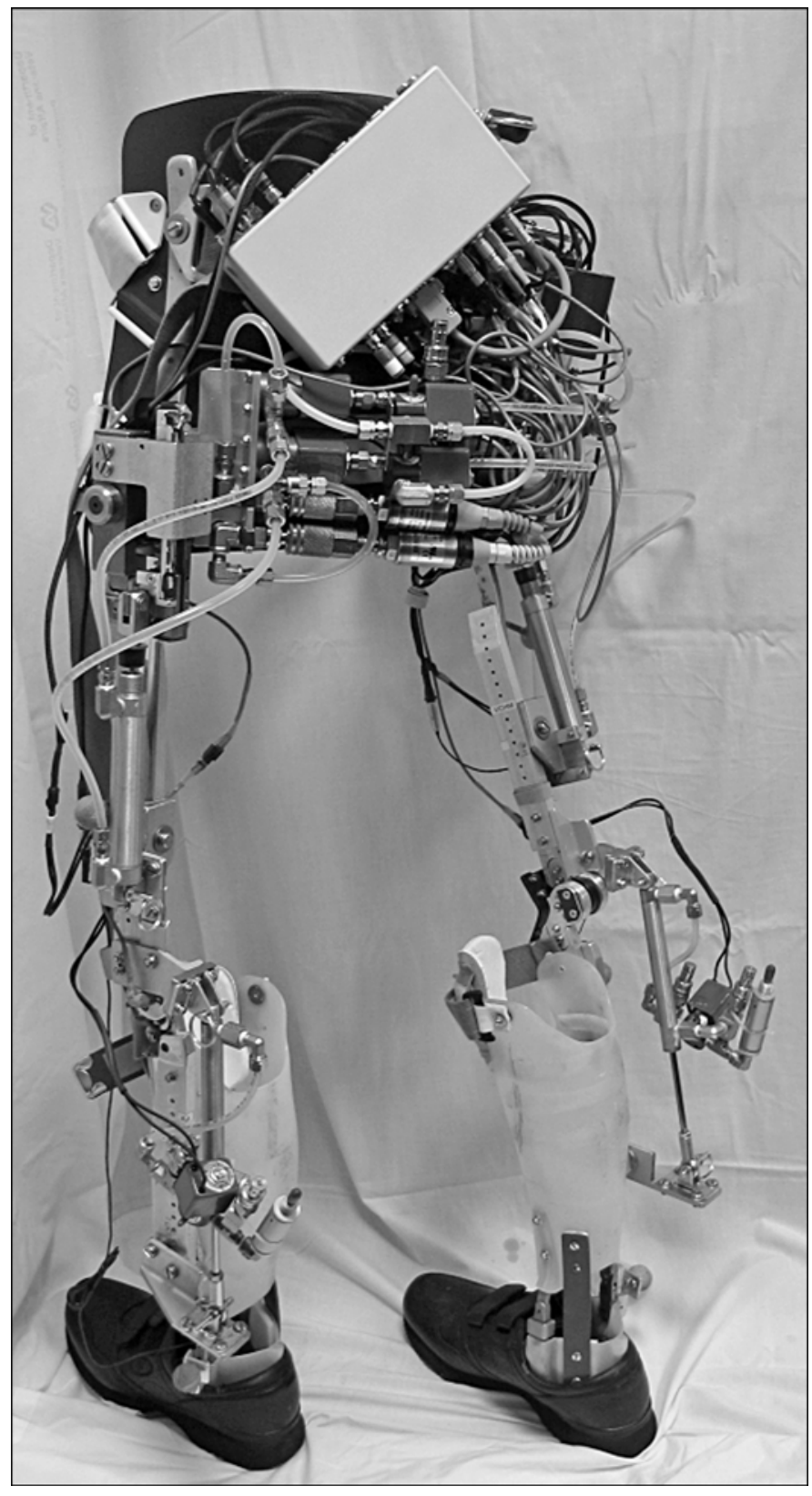

Figure 1.

Variable hip constraint mechanism exoskeleton. Source: Image used with permission by Mr. Rudi Kobetic, Cleveland Department of Veterans Affairs.

includes 16 channels of intramuscular stimulation, which collectively control the hip, knee, and ankle extensor and flexor muscles, including the hip abductors and trunk extensors. The FES system is preprogrammed with a set of stimulation parameters to generate gait. Hybrid control is achieved by means of a finite-state machine that detects 
gait events and sends those events to both the FES stimulator and exoskeleton controller. FES-driven gait works in an open-loop, and the exoskeleton can block or release the knee joints and couple or uncouple the hip joints.

The effects of the hybrid neuroprosthesis on kinematics were studied in five nondisabled subjects and compared with an RGO and nondisabled gait. Knee and hip kinematics when the subjects walked with the hybrid neuroprosthesis resembled a nondisabled pattern. Hip kinetics were also improved when the finite-state machine of the hydraulic hip mechanism was enabled [58]. This represented a remarkable improvement over the RGO with a fixed hip-coupling ratio. However, the total weight of the system (22 kg) reduced gait speed (25\% lower) and increased muscle activation.

The effect of the hybrid neuroprosthetic system on knee kinematics was also studied in a subject with paraplegia resulting from complete SCI (thoracic [T] 7, American Spinal Injury Association [ASIA] A) [56], although no details on gait performance or energy expenditure were reported. As in nondisabled subjects, this hybrid system may result in energy exhaustive gait. More research is pending to extend the benefits of the variable hip coupling mechanisms to rehabilitation outcomes.

\section{Controlled-Brake Orthosis}

The concept of controlling the joint movement generated by FES with joint brakes was first proposed by Durfee and Hausdorff [51]. Following this concept, the controlledbrake orthosis (CBO) with 8 degrees of freedom and four FES channels has been developed (Figure 2) [59-60]. In this system, FES is applied to the quadriceps and peroneal nerve to generate knee extension and a flexion reflex, respectively, while the orthosis controls the knee and hip flexion-extension using magnetic brakes. The ankle is driven by an elastic actuator that controls the dorsal flexion to avoid foot drop; free hip adduction-abduction is provided with a limited range of movement [59]. This configuration results in a light orthosis (6 kg) with highly backdrivable joint actuators (magnetic brakes).

The control strategy (Figure 3) relies on the use of joint brakes to control the position and velocity generated by FES. The joint position error and brake torque are used to detect excessively low and high levels of stimulation, respectively. Both parameters are integrated on the basis of one step and combined in a weighted difference. The amplitude of muscle FES is controlled as a function of trajectory and torque error, averaged on a step-by-step

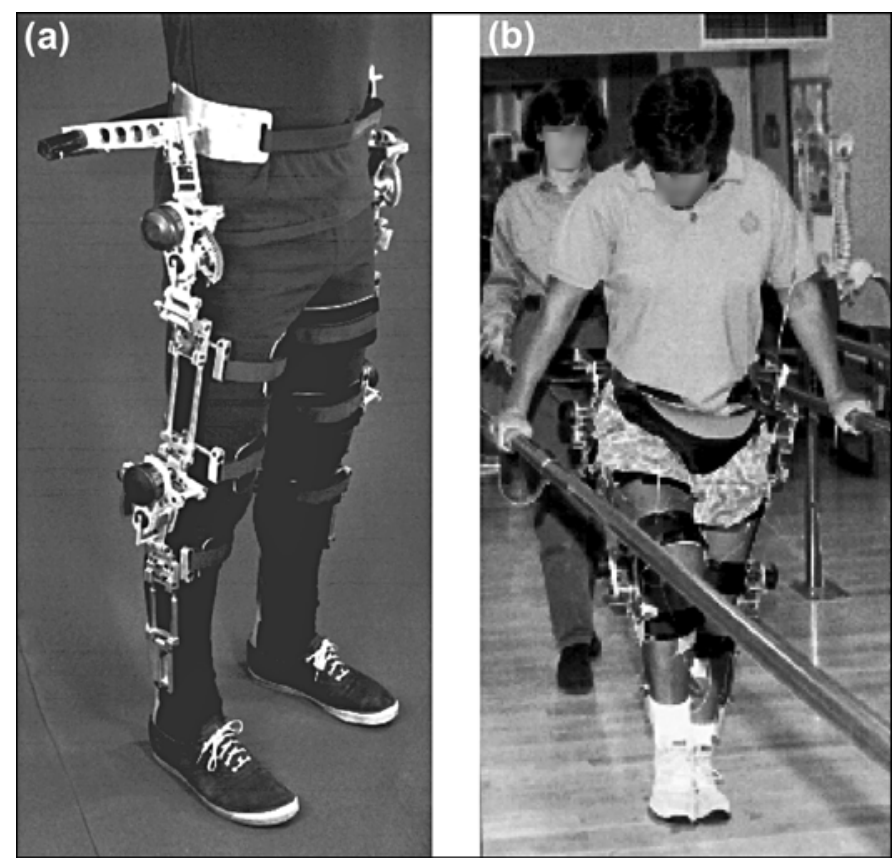

Figure 2.

(a) Controlled-brake orthosis (CBO) exoskeleton. (b) $\mathrm{CBO}$ under clinical trial. Source: Images used with permission by Dr. Michael Goldfarb, Vanderbilt University.

basis to stimulate the muscles with the amplitude necessary to achieve joint movement [60] (Figure 3). As a result, this combined metric acts as an FES regulator on the next step [60]. With this control strategy, the CBO system is the only system that attempts to actively control muscle fatigue by closing the FES loop.

This hybrid approach was first evaluated in a subject with paraplegia resulting from complete SCI (T6). The results with the $\mathrm{CBO}$ revealed a reduction in the duty cycle of muscle stimulation from 85 percent during FES gait to 10 percent with the hybrid system and an improvement in knee trajectory with respect to FES-only gait [60]. However, the flexion reflex was found to change considerably with time, leading to poor performance at the hip joint. A further evaluation was later performed in a study on four subjects with complete and incomplete paraplegia resulting from SCI (ranging from T7 complete to T8 incomplete). This study evaluated the performance of the CBO in terms of muscle fatigue, metabolic cost, and gait performance when compared with FES-only gait [61]. One subject increased walking speed, while distance increased in two subjects. Muscle fatigue was also assessed by measuring the quadriceps isometric recruitment curve as the 


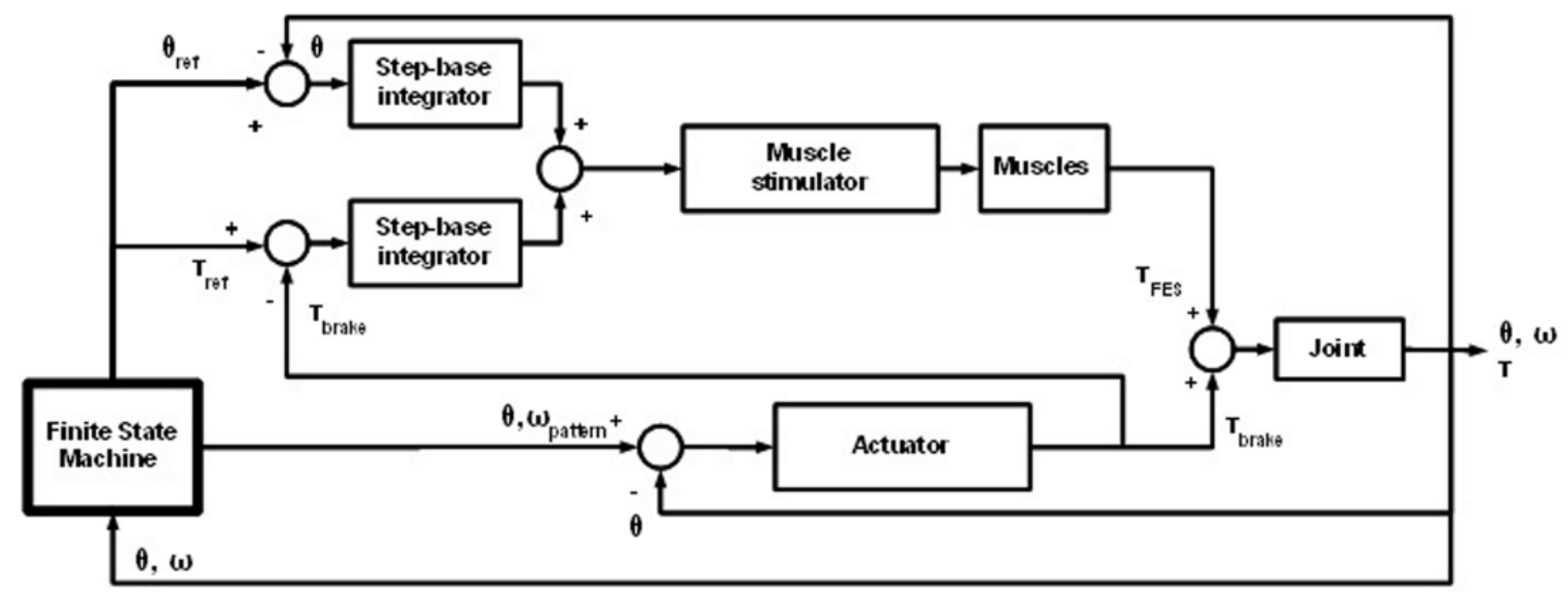

Figure 3.

Controlled-brake orthosis control scheme. $\theta=$ joint angle, $\omega=$ joint angular velocity, FES $=$ functional electrical stimulation, ref $=$ reference, $\mathrm{T}=$ torque.

relative decrease in peak torque. This parameter revealed a lower torque decrease when using the CBO. This study also investigated the relative effects on metabolic cost when using the CBO rather than FES alone, in terms of heart rate, blood pressure, and oxygen consumption. No differences were observed between the two systems.

As previously mentioned, CBO actively manages muscle fatigue by controlling FES amplitude based on the effect of FES on the joint trajectory. Another approach followed by other groups to manage muscle fatigue depends on the optimization of the stimulation strategy and the use of energy storage. By the combined use of an elastic element and a joint brake, it is possible to store the energy from quadriceps stimulation during swing, which is the less demanding condition for the muscle, and release the energy in another phase of gait or joints. Therefore, the need to stimulate the muscles is reduced by the combined use of joint brakes for the stance phases of gait and the use of energy storage. Also, stored spring energy could be used to replace stimulation of the hip flexors or withdrawal reflex, which has shown low effectiveness for eliciting hip flexion [50,61].

\section{Spring-Brake Orthosis}

One of the hybrid orthoses with energy storage is the spring-brake orthosis developed by Gharooni et al. [6263]. In this system, knee flexion after toe-off is generated by the energy released by a spring, which also causes the hip to flex because of gravity action, therefore driving the hip and knee joints to a flexed equilibrium position [62]. At midswing, knee extension is achieved by quadriceps stimulation, at the maximum intensity which is safe and can be tolerated by the subject, to accelerate the shank until the knee reaches full extension. Extension of the knee during this phase restores energy in the spring placed at the knee actuator [63]. A fuzzy inference system determines burst duration to control knee joint kinematics on the basis of knee joint position and velocity error [62], but recently a proportional-integral-derivative (PID) controller has been introduced [64]. Gharooni et al.'s FES control system is intended to achieve the limb's maximum acceleration in the shortest period of time to minimize muscle fatigue, whereas hip and knee joint brakes are used to give support during stance phase [62]. A preliminary test on a nondisabled subject was reported as a proof-of-concept in which the knee and hip kinematics were addressed as a result of combined FES, joint brakes, and energy storage at the knee actuator [62-63].

\section{Joint-Coupled Orthosis}

The joint-coupled orthosis was developed based on the elastic-energy storage concept, but in this case, the elastic element acts across both hip and knee joints [65]. A unidirectional mechanical coupling allows a spring to bias the knee and hip joints toward an equilibrium position in which both joints are flexed; therefore, flexion of the knee 
generates hip flexion. The exoskeleton also has hip and knee friction brakes that provide control of hip and knee joints during the stance phase and release after toe-off. As in the former hybrid exoskeleton, two FES channels are used to stimulate quadriceps muscles of both legs at the peak of hip flexion, which fully extends the knee during the swing phase and also stores energy in the spring [65-66]. In this case, FES pulse parameters are fixed and the stimulation timing is not controlled. A preliminary evaluation of walking performance was performed on 10 nondisabled subjects wearing the exoskeleton on one leg. The experiments consisted of three cycles of 5 minutes walking and 1 minute relaxation while measuring the range of knee movement. While the range of knee movement was reduced during the first three cycles, it then stabilized at 85 percent of the range of movement measured at the beginning of the experiment [65]. These results indicate that this energy storage approach may delay the onset of muscle fatigue, although to our knowledge, the performance of this system has not been evaluated with SCI subjects.

\section{Energy-Storing Orthosis}

A hybrid exoskeleton that stores energy from the stimulation of the quadriceps muscles has also been developed [67]. A peculiarity of this system is that the energy-storing orthosis (ESO) uses the energy-storing concept to decouple hip extension and flexion; pneumatic circuitry is used to extract, store, transfer, and release energy from the quadriceps to the hip [67-68]. Also, elastic actuators are included to keep the hip and knee joints in a flexed equilibrium position [67,69]. At midswing, the quadriceps is stimulated and the knee extends, storing energy in the pneumatic accumulator. Simultaneously, energy is also stored in the elastic storage element at the knee joint. After full extension, the knee is locked and energy is released into the hip actuator and the hip extends, enabling forward progression and storing energy in the hip elastic storage element. Therefore, this pneumatic system allows decoupling control of hip and knee joints. A wrap spring brake controls joint trajectory and gives joint support during stance [67-68]. An optimized version of this design with rubber bands as the elastic elements was tested on a subject with paraplegia resulting from SCI injury (T12) [69]. However, the results of this preliminary evaluation were limited to safety and fitting functions of the orthosis, and thus, no conclusions can be made with respect to gait parameters.

\section{Hybrid Exoskeletons Controlled by Active Joint Actuators}

The main drawback of the hybrid exoskeletons controlled by joint brakes is the inability to provide full control of the joint, since joint brakes are not capable of delivering torque. Therefore, movement is generated only by the muscular action due to FES; since most systems perform an open-loop control of FES, movement quality is low in terms of joint trajectory and velocity. Furthermore, the insufficient joint power obtained, especially with the flexion withdrawal reflex, renders the control system ineffective. Moreover, the appearance of muscle fatigue due to FES is difficult to manage, especially because of the decrease in joint power and joint trajectory.

Therefore, in contrast to joint brake hybrid exoskeletons, active actuator hybrid exoskeletons allow control of the power delivered at the joint, therefore performing an effective closed-loop control of joint movement.

\section{Hybrid Assistive System}

One of the first hybrid systems developed and tested [50] was based on an existing concept, the self-fitting modular orthosis (SFMO) [70]. To develop the hybrid assistive system (HAS), the SFMO was configured with a lightweight knee-ankle brace equipped with a direct current (DC) servomotor and a motor-driven drum brake coupled to the knee joint with a ball screw. The actuator delivers power or provides externally powered and controlled extension and flexion in addition to stiffness control from locked to free. The ankle joint is actuated by a spring mechanism to control dorsal flexion. The FES system consists of six channels acting on the gluteus medius for balance; the quadriceps for hip flexion and knee extension; and the peroneal nerve to generate the flexion reflex, allowing knee, hip, and ankle dorsal flexion. The stimulation parameters for each channel are fixed following prior calibration of the subject. Potentiometers are used to measure joint rotation. Force transducers and switches on walkers or crutches are used to detect external loading.

Initial results with the HAS focused on testing finitestate control algorithms to combine brake, motor, and muscle stimulation. Further evaluation with a patient who suffered an incomplete cervical (C) 5/6 lesion with no voluntary control of the lower limbs compared walking performance with three systems: SFMO only, FES only, and HAS. The results with HAS revealed a small improvement in gait velocity and physiological cost (measured by 
oxygen consumption) with respect to other systems. However, the knee flexion reflex generated by the HAS can be problematic, with flexion deteriorating after $10 \mathrm{~min}$ of walking, limiting gait duration [50].

\section{Hybrid Powered Orthosis}

The active control of hip and knee joints by means of actuators was also explored with the hybrid powered orthosis (HyPo) [71]. The HyPo is designed with the motors and gearboxes located in the front part of the orthosis, allowing users to wear it while sitting. DC motors (70 W, $0.14 \mathrm{Nm}$ ) and gearboxes (156:1) are included to control the hip and knee joints of both legs, allowing the gait to be generated without FES. Open-loop FES is used for the quadriceps of both legs, while the DC motors are used for compensation of joint trajectories with proportional control of position and velocity. Note that in this case, the actuators are dimensioned to allow the generation of gait without FES, therefore taking into account that muscle fatigue can make FES useless for walking. FES pattern and joint control are synchronized throughout an entire gait cycle because no information is provided to discriminate between stance and swing. The optimization of the FES patterns for knee joint movement was reported as a proof-of-concept, although no quantitative data were included in this study.

\section{WalkTrainer}

The WalkTrainer was developed as a hybrid exoskeleton with closed-loop control of FES that relies on an estimate of the interaction forces between the user and the exoskeleton [72]. The WalkTrainer exoskeleton controls hip, knee, and ankle joints, as well as pelvis movement, with 6 degrees of freedom, and it is attached to a moving frame that supports the exoskeleton and the user via a weight-bearing system similar to treadmill training systems (Figure 4). Motorized wheels assist walking with the exoskeleton. The FES closed-loop controller combines the feed-forward model of the torque-intensity characteristics of the muscle involved in the movement and a classic PID controller to compensate for torque error, while the DC motors control joint trajectories [73]. The joint torque exerted by the user is estimated based on structural forces that result from the interaction of the body segments and the exoskeleton. The system is intended to minimize such interaction forces by modulating muscle stimulation during walking.

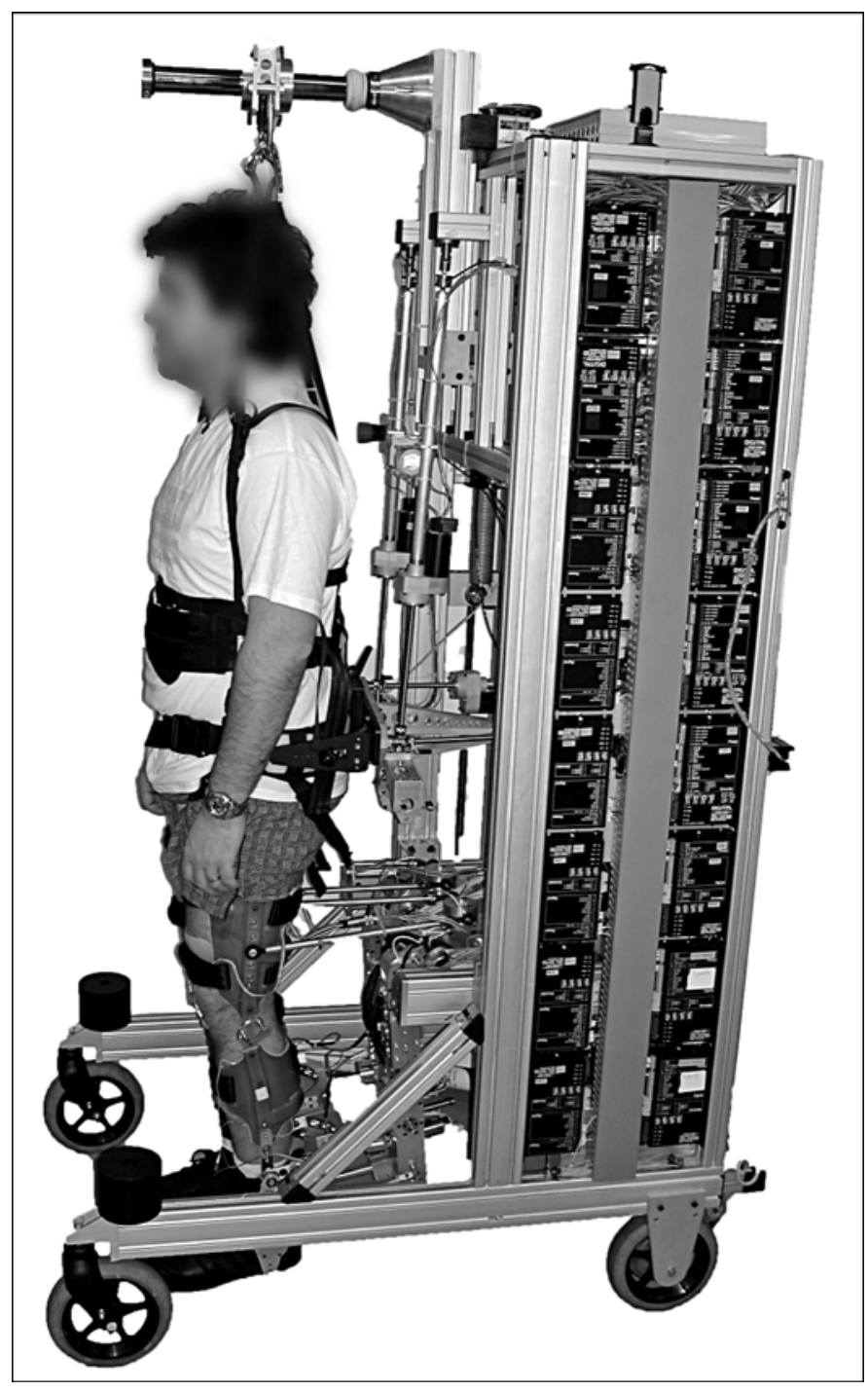

Figure 4.

WalkTrainer. Source: Image used with permission by Dr. Mohamed Bouri, EPF Lausanne.

A preliminary clinical evaluation of the WalkTrainer was performed on six subjects with paraplegia due to SCI lesions. Two of the subjects had complete paraplegia (ASIA A) and four had incomplete paraplegia (1 ASIA C and 3 ASIA D), although no information on the level of the lesion was provided [72]. The experiments consisted of trials of 1 hour a week for 12 weeks, resulting in a reduction in the Ashworth Spasticity Scale. This FES closed-loop control scheme formed the basis to develop several other systems: the MotionMaker [73-75], a stationary programmable test and training system for the lower limbs, and the 
Lambda [76], a training system for the lower limbs based on an end effector controller. Although the MotionMaker and Lambda systems are regarded as hybrid exoskeletons, they are beyond the scope of this review, which focused on hybrid exoskeletons intended to compensate gait.

\section{DISCUSSION}

\section{Main Achievements}

The hybrid exoskeletons reviewed here demonstrate the feasibility of combining FES with an exoskeleton to provide joint control and reduced energy demand. Various approaches have been used to combine FES with an exoskeleton, and the FES systems reviewed range from implanted systems with up to 16 channels [56] to singlechannel stimulation $[62,66,68]$. The exoskeletons are designed to provide joint support during stance and trajectory control by means of brakes or clutches $[59,62,66,68]$.
Other exoskeletons have active actuators that can either dissipate or add power to the joints, thereby providing a means of control while allowing complete joint movement to improve system performance [50,71-73].

Among the systems reviewed, the simplest means of implementing a hybrid control strategy is to use open-loop electrical stimulation and closed-loop joint movement or torque by means of an actuator (e.g., brakes $[56,66,68]$ or motors [50,77]) (Figure 5). Although open-loop stimulation can be improved with feed-forwarding from a muscle model [51,78-79], the identification of nonlinear, timedependent muscle characteristics is not mature enough yet to be implemented in ambulatory systems.

This control strategy has the disadvantage that no information about joint movement or the torque produced by FES is fed into the FES controller, and therefore, there is no direct muscle control. Closed-loop muscle stimulation in a hybrid configuration is a complex task that depends on the availability of robust parameters directly

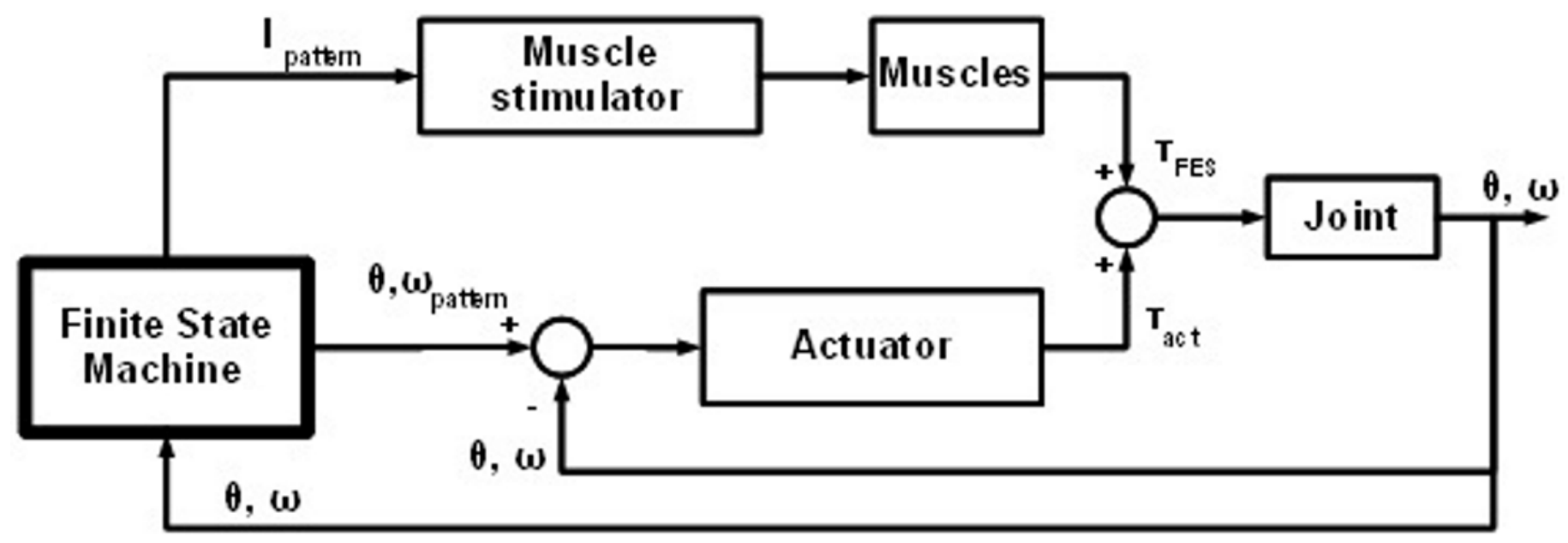

Figure 5.

Functional electrical stimulation (FES)-open loop control scheme. Variants of this control scheme are implemented in Popovic et al. [1], Kobetic et al. [2], Farris et al. [3], Kangude et al. [4], and Obinata et al. [5]. $\theta=$ joint angle, $\omega=$ joint angular velocity, act $=$ actual, $\mathrm{I}=$ inertia, $\mathrm{T}=$ torque.

1. Popovic D, Tomovi R, Schwirtlich L. Hybrid assistive system-the motor neuroprosthesis. IEEE Trans Biomed Eng. 1989;36(7): 729-37.

2. Kobetic R, To CS, Schnellenberger JR, Audu ML, Bulea TC, Gaudio R, Pinault G, Tashman S, Triolo RJ. Development of hybrid orthosis for standing, walking, and stair climbing after spinal cord injury. J Rehabil Res Dev. 2009;46(3):447-62.

3. Farris RJ, Quintero HA, Withrow TJ, Goldfarb M. Design and simulation of a joint-coupled orthosis for regulating FES-aided gait. 2009 IEEE 11th International Conference on Rehabilitation Robotics; 2009 Jun 23-26; Kyoto, Japan. Piscataway (NJ): IEEE; 2009. p. 1916-22.

4. Kangude A, Burgstahler B, Kakastys J, Durfee W. Single channel hybrid FES gait system using an energy storing orthosis: preliminary design. Conf Proc IEEE Eng Med Biol Soc. 2009;2009:6798-6801.

5. Obinata G, Ogisu T, Hase K, Kim Y, Genda E. State estimation of walking phase and functional electrical stimulation by wearable device. Conf Proc IEEE Eng Med Bio Soc. 2009;2009:5901-4. 
related to muscle performance. Some indirect measurements have been proposed in order to estimate muscle performance under FES for hybrid closed-loop control. These include using FES-induced joint movement to estimate the timing of stimulation in order to minimize muscle fatigue [62-63] or using the interaction forces between the exoskeleton and the legs [72,74-75,80] to generate a specific joint torque pattern (Figure 6). Combining these two approaches, the CBO scheme controls FES amplitude on the basis of both position and the torque error produced by the electrical stimulation, aiming at a reference joint movement during the swing phase (Figure 3) [60].

Managing muscle fatigue is a critical factor in the design of a hybrid exoskeleton, because of the unnatural aspect of muscle recruitment with current FES systems, which leads to early muscle fatigue. This effect is critical in cases of muscle atrophy, which are typically found in the SCI population. Various approaches have been used to address the issue of muscle fatigue. One approach is to minimize the muscle stimulation duty cycle. This has been tested using joint brakes that block the joints during the stance phase, eliminating the need for stimulation in this demanding phase [56,59,62,65,67]. Extending this concept, other approaches store energy from the quadriceps muscle during swing, taking advantage of the power of the quadriceps muscle and its accessibility to surface electrodes. The stored energy can then be released and transferred to generate hip flexion [62,65] or extension [67]. In an experiment performed with nondisabled subjects [66],

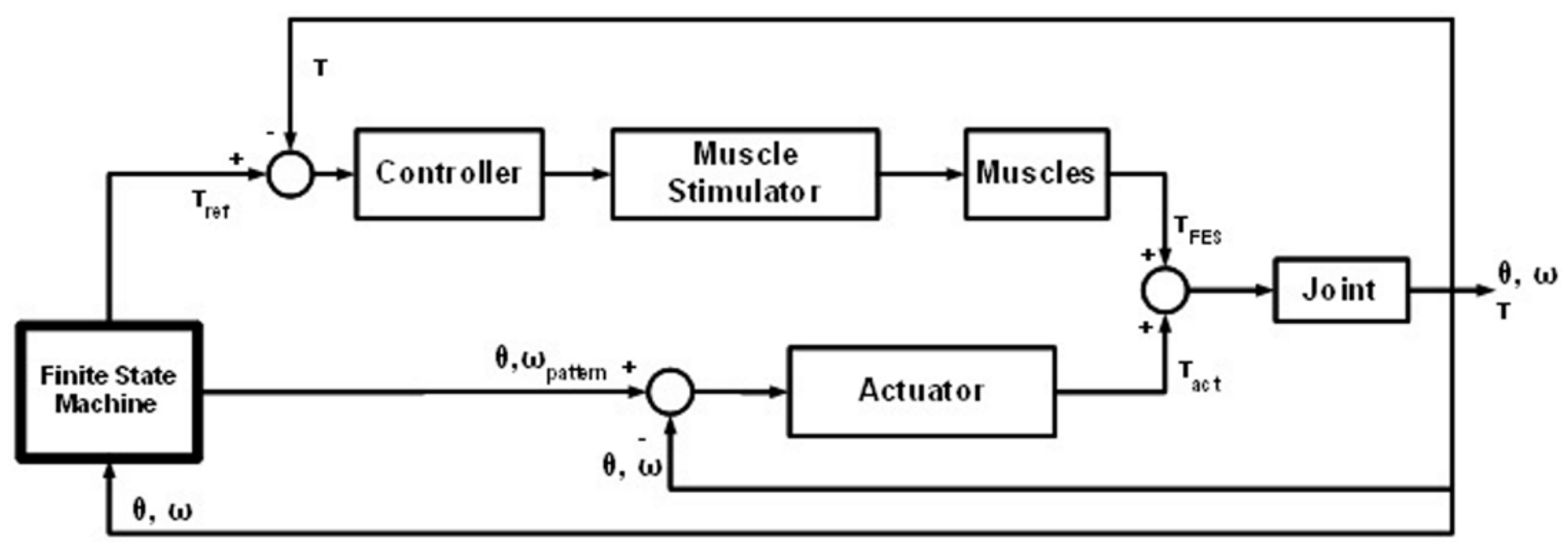

Figure 6.

Functional electrical stimulation (FES)-closed loop control scheme. Variants of this control scheme are implemented in Gharooni et al. [1-2], Stauffer et al. [3], Metrailler et al. [4-5], and Schmitt et al. [6]. $\theta=$ joint angle, $\omega=$ joint angular velocity, act $=$ actual, ref $=$ reference, $\mathrm{T}=$ torque.

1. Gharooni S, Tokhi MO, Heller B. The use of elastic element in a hybrid orthosis for swing phase generation in orthotic gait. Proceedings of the Annual Conference of the International Functional Electrical Stimulation Society; 2000; Aalborg, Denmark. 2000.

2. Gharooni S, Heller B, Tokhi MO. A new hybrid spring brake orthosis for controlling hip and knee flexion in the swing phase. IEEE Trans Neural Syst Rehabil Eng. 2001;9(1):106-107.

3. Stauffer Y, Allemand Y, Bouri M, Fournier J, Clavel R, Metrailler P, Brodard R, Reynard F. The WalkTrainer-a new generation of walking reeducation device combining orthoses and muscle stimulation. IEEE Trans Neural Syst Rehabil Eng. 2009;17(1):38-45.

4. Metrailler P, Blanchard V, Perrin I, Brodard R, Frischknecht R, Schmitt C, Fournier J, Bouri M, Clavel R. Improvement of rehabilitation possibilities with the MotionMaker TM. Proceedings of the First IEEE/RAS-EMBS International Conference on Biomedical Robotics and Biomechatronics; 2006 Feb 20-22; Pisa, Italy. Piscataway (NJ): IEEE; 2006. p. 359-64.

5. Metrailler P, Brodard R, Clavel R, Frischknecht R. Closed loop electrical muscle stimulation in spinal cord injured rehabilitation. Proceedings of the Mediterranean Forum of Physical and Rehabilitation Medicine; 2006 Oct 18-21; Villamura, Portugal; Lausanne, Switzerland (Infoscience, EPFL); 2006.

6. Schmitt C, Metrailler P, Al-Khodairy A, Brodard R, Fournier J, Bouri M, Clavel R. The MotionMaker: A rehabilitation system combining an orthosis with closed loop electrical muscle stimulation. Proceedings of the 8th Vienna International Workshop on Functional Electrical Stimulation; 2004 Sep 10-13; Vienna, Austria; 2004. p. 117-20. 
muscle fatigue was addressed by measuring the range of knee movement during a walking trial with the exoskeleton. This range of movement stabilized at 85 percent of the initial steps, indicating that this approach maintains the level of muscle fatigue in nondisabled subjects [65-66], although no results from SCI subjects are available. While this is an energy-efficient strategy, it cannot be regarded as a rehabilitation approach because it is restricted to a single leg muscle and the stimulation pattern does not resemble normal muscle activation during nondisabled gait.

A second approach involves the management of FES parameters based on indirect evaluation of muscle fatigue. Using this approach, the CBO controls FES amplitude in function of the position and torque error resulting from stimulation. The position error is used to detect when muscle performance is insufficient to achieve the trajectory, while the brake torque is used to detect excessive stimulation intensity. Combining the two measures, FES is applied to regulate the next step [60]. However, this approach lacks the ability to compensate joint trajectory when the muscle does not generate enough joint torque to achieve movement. As a result, this strategy is not effective when muscle fatigue or habituation occur [61]. An effective muscle fatigue strategy within the framework of rehabilitation involves the implementation of active actuators on the exoskeleton, allowing muscle relaxation while performing functional movement by changing the stimulating parameters, primarily the intensity. A similar approach was considered in the development of the WalkTrainer by monitoring the current delivered by the FES and the joint power generated by the muscles through force sensors on the exoskeleton. It is hypothesized that as long as muscle fatigue appears, more stimulation must be delivered to the muscles to maintain the power generated at the joints. However, no detailed information on the control strategy when muscle fatigue appears has been reported [74].

Because hybrid systems are intended for subjects with SCI, a preliminary evaluation in such patients is critical. Some systems have been tested with nondisabled subjects to verify the capacity of the orthosis to provide safe single- and double-stance support and to detect gait transitions [56,58,65,69]. In other studies, the nondisabled tests served to assess the control strategy more than the safety issues [62,77]. Safety and comfort are issues that must be considered in the design process and must be verified before SCI testing. Functional evaluation with end-users is an area in which we have detected little consensus in the methods and measures used to evaluate such systems. User evaluation is crucial to generate useful information about the functional performance of hybrid exoskeletons. While testing in both nondisabled subjects [62-63,65-66,71] and SCI subjects has been reported for some systems, the number of subjects is generally limited and heterogeneous. For example, the CBO was tested on four patients with SCI [60-61] and the variable hip constraint mechanism was tested on only one subject with T7 complete paraplegia [56]. The HAS was only studied on one case with C5/6 incomplete tetraplegia [50], and similarly, the ESO was tested on one subject with T12 complete paraplegia [69]. Preliminary results from the evaluation of the WalkTrainer were published from a study of six subjects with SCI without information on the neurological level of the SCI [72]. Moreover, in some cases, the subject characteristics are not homogeneous and combine complete and incomplete SCI subjects in the same test protocol $[61,72]$. Because of the complexity and heterogeneity of SCI, even when the same levels of lesion are considered, the data obtained frequently lack reliability and are insufficient to produce valid conclusions, even though marked tendencies may be apparent. Thus, performing these evaluations in larger populations of SCI subjects and in groups more homogeneous with respect to lesion level and degree of severity (complete or incomplete) appears to be necessary.

The systems reviewed in this article assessed performance in SCI patients [50,56,60-61,69,72] by evaluating walking with the hybrid system while certain variables were recorded. A wide range of variables are reported, which can be classified as gait kinematics variables, temporal-spatial gait variables, physiological cost variables, and other variables related to gait function. Gait kinematics are easy to obtain and provide valuable information about the joint control offered by the hybrid system [56,61,72], although they are not reported in some studies [50,69]. Temporal-spatial variables such as speed, walking distance, step length, and cadence are reported in most of the studies reviewed [50,56,58,61]. The physiological cost variables are a set of variables intended to assess the metabolic cost associated with the hybrid system. The physiological cost was not evaluated for all the systems reviewed here, and where it was, different variables were used: oxygen consumption normalized as an indirect measure of the physiological cost [50], heart rate, and blood pressure [60-61]. Muscle fatigue has also been related to the physiological cost [60-61,72], assuming that a decrease in the stimulation cycle leads to a decrease 
in muscle fatigue [62-63,65-66,71]. Other variables analyzed are related to spasticity, coordination [72], and system comfort [69].

\section{Challenges}

While the different approaches described demonstrate the feasibility of the hybrid exoskeleton concept, management of muscle performance during walking has proved challenging when a hybrid exoskeleton is used to rehabilitate gait. To extend the benefits of FES-aided gait to functional rehabilitation, the control strategy must modulate stimulation to delay muscle fatigue and thereby increase the usage time and walking distance. This modulation must be based on information on muscle performance, which can be estimated from the interaction between the legs and the exoskeleton $[72,81]$ until more precise neuromuscular models are developed. Such models will have to consider the nonlinearity and time-dependent characteristics of the musculoskeletal system. The performance of artificially controlled muscles will also improve when novel stimulation techniques are adapted to hybrid exoskeletons, such as the use of discrete matrix electrodes instead of surface electrodes [82].

Closed-loop control of FES in the hybrid strategy can also provide the flexibility required to implement strategies under the "assist-as-needed" concept, which along with user involvement is thought to be essential to promote rehabilitation in incomplete SCI [83-84]. The latter is the main area in which hybrid exoskeletons offer advantages over robotic treadmill trainers, in which user involvement is difficult to obtain [85]. The assist-as-needed paradigm will help to provide user assistance regarding subjects' residual function; hybrid exoskeletons must be able to assess residual physical abilities (voluntary muscle force, joint range of motion, bioelectrical residual activity) as well as sensory-motor function in order to adapt their performance and mode of operation according to the specific residual function. This can be realized through different modes of FES implementations as well as novel hybrid FES-robot control paradigms. To our knowledge, the assist-as-needed paradigm has not yet been implemented in the field of hybrid exoskeletons, probably because most of the designs are intended to develop energy-efficient systems to restore gait function. Although reducing energy demand allows for the development of more portable exoskeletons, it cannot be expected to provide any long-term improvement in the functional ability of the user. However, a control approach combining the assist-as-needed paradigm with a maximization of user involvement may lead to a long-term improvement in the user's functional abilities.

All the hybrid exoskeletons reviewed in this article have undergone some form of preliminary evaluation focused on aspects of the exoskeletons' safety and energy performance. However, the effects of the external (exoskeleton) and internal (muscles) sources of joint torque on pathological joints have yet to be assessed. Thus, while these systems are functional (i.e., they stabilize the joints during stance), no criteria exist regarding the optimum balance between the exoskeleton and muscle joint torque, based on objective knowledge of the influence of the hybrid system on the joints.

The peculiarities of subjects with SCI hamper the extrapolation of performance testing results. For example, the location of the muscles affected, muscular atrophy in the chronic phase of the injury, impaired sensation and decreased physical capacity are clearly differentiating factors that require specific clinical evaluation in patients with SCI. The systems included in this review either lack data relating to testing in SCI subjects [58,65-66] or the number of subjects is insufficient to confidently link the findings to the hybrid systems [50,54,56,59,61,72]. Furthermore, the metrics used to evaluate hybrid exoskeletons vary considerably across studies. We believe that other parameters usually used in a clinical setting to quantify gait function may be more suitable for evaluating the performance of these systems within the scope of the pathology. Walking speed (10 m walking test [10MWT]), walking distance (6-minute walking test [6MWT]) and the Walking Index for Spinal Cord Injury Version 2 (WISCI II) are three scales used to quantify muscle weakness due to paralysis, and they have been evaluated for their utility, validity, and reliability in clinical practice and as research tools [86]. Moreover, the combination of 10MWT, WISCI II, and 6MWT could represent the most valid measure of improvements in gait and ambulation [87], providing an objective tool to measure gait improvement when comparing the hybrid exoskeleton with other approaches. A comprehensive evaluation of the performance of a hybrid system should include a combination of variables, such as joint kinematics and kinetics, gait function scales (10MWT, 6MWT, WISCI II), and parameters related to physiological costs, such as oxygen consumption and muscle fatigue during use. 


\section{CONCLUSIONS}

Gait restoration is considered to be a high priority among SCI patients. To restore walking gait, different approaches have been developed, each with its own particular limitations. Hybrid exoskeletons are emerging as a promising approach that blends complementary robotic and neuroprosthetic technologies.

Two main types of hybrid exoskeletons exist based on the exoskeleton's driving principle: braking or active. The state of the art demonstrates that hybrid technologies can produce feasible systems in which the exoskeleton provides FES with adequate control of joint movement, reducing the system's energy requirements. Management of muscle fatigue is addressed by development of optimized systems that minimize the need for muscular stimulation or by active control of stimulation by closing the FES control loop. Nevertheless, many challenges remain. Effective closed-loop control of FES will enable implementation of real-time strategies to manage muscle performance. Assistas-needed control strategies must also be implemented, taking advantage of neuroprosthetic and robotic systems that work in parallel with the human system. These systems should be used to promote user involvement by having them perform gait in a real environment, probably the most challenging situation in which to develop movement. Clinical evaluation must be comprehensive, addressing gait performance, user-perception, and physiological cost through clinically validated functional scales and protocols.

\section{ACKNOWLEDGMENTS}

\author{
Author Contributions: \\ Article concept and design: A. J. del-Ama, J. C. Moreno. \\ Literature search: A. J. del-Ama, A. D. Koutsou, A. de-los-Reyes. \\ Analysis and interpretation of published work: A. J. del-Ama, \\ J. C. Moreno, A. D. Koutsou, A. de-los-Reyes. \\ Drafting of manuscript: A. J. del-Ama, A. D. Koutsou. \\ Critical revision of manuscript for important intellectual content: \\ J. L. Pons, J. C. Moreno, A. Gil-Agudo. \\ Obtained funding: J. L. Pons. \\ Article coordination and supervision: J. C. Moreno.
}

Financial Disclosures: The authors have declared that no competing interests exist.

Funding/Support: This material was based on work performed as part of the project "Sistemas avanzados EEF y UMI para el desarrollo de soft-robots en el ámbito de la robótica de rehabilitación” supported by the Ministerio de Educación y Ciencia (grant DPI2008-06772C03-01) and the 7th Framework Programme (grant CSD2009-00067 CONSOLIDER INGENIO 2010).
Additional Contributions: The authors would like thank to Dr. Mohamed Bouri, Mr. Thomas Bulea, Dr. William K. Durfee, Dr. Michael Goldfarb, and Mr. Rudi Kobetic for their original material.

\section{REFERENCES}

1. Maynard FM Jr, Bracken MB, Creasey G, Ditunno JF Jr, Donovan WH, Ducker TB, Garber SL, Marino RJ, Stover SL, Tator CH, Waters RL, Wilberger JE, Young W; American Spinal Injury Association. International standards for neurological and functional classification of spinal cord injury. Spinal Cord. 1997;35(5):266-74. [PMID:9160449] http://dx.doi.org/10.1038/sj.sc.3100432

2. Cooper RA, Ohnabe H, Hobson DA. An introduction to rehabilitation engineering. Winter Park (FL): CRC Press; 1995.

3. Anderson KD. Targeting recovery: priorities of the spinal cordinjured population. J Neurotrauma. 2004;21(10):1371-83. [PMID:15672628] http://dx.doi.org/10.1089/neu.2004.21.1371

4. Ditunno PL, Patrick M, Stineman M, Ditunno JF. Who wants to walk? Preferences for recovery after SCI: a longitudinal and cross-sectional study. Spinal Cord. 2008;46(7): 500-6. [PMID:18209742]

http://dx.doi.org/10.1038/sj.sc.3102172

5. Donnelly C, Eng JJ, Hall J, Alford L, Giachino R, Norton $\mathrm{K}$, Kerr DS. Client-centred assessment and the identification of meaningful treatment goals for individuals with a spinal cord injury. Spinal Cord. 2004;42(5):302-7.

[PMID:14993893] http://dx.doi.org/10.1038/sj.sc.3101589

6. Estores IM. The consumer's perspective and the professional literature: what do persons with spinal cord injury want? J Rehabil Res Dev. 2003;40(4 Suppl 1):93-98. [PMID:15077653] http://dx.doi.org/10.1682/JRRD.2003.08.0093

7. Kilgore KL, Scherer M, Bobblitt R, Dettloff J, Dombrowski DM, Godbold N, Jatich JW, Morris R, Penko JS, Schremp ES, Cash LA. Neuroprosthesis consumers' forum: consumer priorities for research directions. J Rehabil Res Dev. 2001;38(6):655-60. [PMID:11767973]

8. Merrit JL, Yoshida MK. Knee-ankle-foot orthoses: indications and practical applications on long leg braces. Phys Med Rehabil State of the Art Rev. 2000;14:395-422.

9. Waters RL, Lunsford BR. Energy cost of paraplegic locomotion. J Bone Joint Surg Am. 1985;67(8):1245-50. [PMID:4055849]

10. Yngve DA, Douglas R, Roberts JM. The reciprocating gait orthosis in myelomeningocele. J Pediatr Orthop. 1984;4(3): 304-10. [PMID:6736234] http://dx.doi.org/10.1097/01241398-198405000-00005 
11. Jaspers P, Peeraer L, Van Petegem W, Van der Perre G. The use of an advanced reciprocating gait orthosis by paraplegic individuals: a follow-up study. Spinal Cord. 1997;35(9): 585-89. [PMID:9300963] http://dx.doi.org/10.1038/sj.sc.3100462

12. Rose GK. The principles and practice of hip guidance articulations. Prosthet Orthot Int. 1979;3(1):37-43. [PMID:471704]

13. Patrick JH, McClelland MR. Low energy cost reciprocal walking for the adult paraplegic. Paraplegia. 1985;23(2): 113-17. [PMID:4000691] http://dx.doi.org/10.1038/sc.1985.19

14. Kirtley C, McKay SK. Principles and practice of paraplegic locomotion: Experience with the Walkabout walking system. Aust Orthot Prosthet Mag. 1992;7(2):4-8.

15. Leung AK, Wong AF, Wong EC, Hutchins SW. The Physiological Cost Index of walking with an isocentric reciprocating gait orthosis among patients with $\mathrm{T}(12)$ - L(1) spinal cord injury. Prosthet Orthot Int. 2009;33(1):61-68.

[PMID:19235067] http://dx.doi.org/10.1080/03093640802562368

16. Lotta S, Fiocchi A, Giovannini R, Silvestrin R, Tesio L, Raschi A, Macchia L, Chiapatti V, Zambelli M, Tosi C. Restoration of gait with orthoses in thoracic paraplegia: a multicentric investigation. Paraplegia. 1994;32(9):608-15. [PMID:7997340] http://dx.doi.org/10.1038/sc.1994.96

17. Franceschini M, Baratta S, Zampolini M, Loria D, Lotta S. Reciprocating gait orthoses: a multicenter study of their use by spinal cord injured patients. Arch Phys Med Rehabil. 1997;78(6):582-86. [PMID:9196464] http://dx.doi.org/10.1016/S0003-9993(97)90422-6

18. Fatone S. A review of the literature pertaining to KAFOs and HKAFOs for ambulation. J Prosthet Orthot. 2006; 18(3):P137-68. http://dx.doi.org/10.1097/00008526-200606001-00003

19. Vukobratovic M, Hristic D, Stojiljkovic Z. Development of active anthropomorphic exoskeletons. Med Biol Eng. 1974; 12(1):66-80. [PMID:4465554] http://dx.doi.org/10.1007/BF02629836

20. Herr H. Exoskeletons and orthoses: classification, design challenges and future directions. J Neuroeng Rehabil. 2009; 6(1):21. [PMID:19538735] http://dx.doi.org/10.1186/1743-0003-6-21

21. Mohammed S, Amirat Y. Towards intelligent lower limb wearable robots: Challenges and perspectives - State of the art. Proceedings of the IEEE International Conference on Robotics and Biomimetics. ROBIO 2008; 2008 Dec 14-17; Bangkok, Thailand. New York (NY): IEEE; 2009. p. 312-17.

22. Dollar AM, Herr H. Lower extremity exoskeletons and active orthoses: Challenges and state-of-the-art. IEEE
Trans Robot. 2008;24(1):144-58.

http://dx.doi.org/10.1109/TRO.2008.915453

23. Ferris DP, Czerniecki JM, Hannaford B. An ankle-foot orthosis powered by artificial pneumatic muscles. J Appl Biomech. 2005;21(2):189-97. [PMID:16082019]

24. Argo Medical Technologies. [Internet]. Yokneam Ilit (Israel): Argo Medical Technologies; c2010 [cited 2012 Mar]. Available from: http://www.argomedtec.com/

25. Ekso Bionics. [Internet]. Berkeley (CA): Ekso Bionics; c2011 [cited 2012 Mar]. Available from:

http://www.eksobionics.com/

26. Popovic MR, Keller T, Pappas IP, Dietz V, Morari M. Surfacestimulation technology for grasping and walking neuroprosthesis. IEEE Eng Med Biol Mag. 2001;20(1):82-93. [PMID:11211664]

http://dx.doi.org/10.1109/51.897831

27. Lyons CL, Robb JB, Irrgang JJ, Fitzgerald GK. Differences in quadriceps femoris muscle torque when using a clinical electrical stimulator versus a portable electrical stimulator. Phys Ther. 2005;85(1):44-51. [PMID:15623361]

28. Kantrowitz A. Electronic physiological aids: A report of the Maimonides Hospital. Brooklyn (NY): Maimonides Hospital; 1960.

29. Liberson WT, Holmquest HJ, Scot D, Dow M. Functional electrotherapy: stimulation of the peroneal nerve synchronized with the swing phase of the gait of hemiplegic patients. Arch Phys Med Rehabil. 1961;42:101-105. [PMID:13761879]

30. Kralj A, Bajd T, Turk R, Krajnik J, Benko H. Gait restoration in paraplegic patients: a feasibility demonstration using multichannel surface electrode FES. J Rehabil Res Dev. 1983; 20(1):3-20. [PMID:6887064]

31. Graupe D, Kohn KH. Transcutaneous functional neuromuscular stimulation of certain traumatic complete thoracic paraplegics for independent short-distance ambulation. Neurol Res. 1997;19(3):323-33. [PMID:9192387]

32. Marsolais EB, Kobetic R. Functional electrical stimulation for walking in paraplegia. J Bone Joint Surg Am. 1987; 69(5):728-33. [PMID:3496340]

33. Kobetic R, Triolo RJ, Marsolais EB. Muscle selection and walking performance of multichannel FES systems for ambulation in paraplegia. IEEE Trans Rehabil Eng. 1997; 5(1):23-29. [PMID:9086382] http://dx.doi.org/10.1109/86.559346

34. Popovic DB, Popovic MB, Dosen S. Neural prostheses for walking restoration. J Autom Control. 2008;18(2):63-71. http://dx.doi.org/10.2298/JAC0802063P

35. Yang L, Condie DN, Granat MH, Paul JP, Rowley DI. Effects of joint motion constraints on the gait of normal subjects and their implications on the further development of hybrid FES orthosis for paraplegic persons. J Biomech. 
1996;29(2):217-26. [PMID:8849815]

http://dx.doi.org/10.1016/0021-9290(95)00018-6

36. Fujita K, Handa Y, Hoshimiya N, Ichie M. Stimulus adjustment protocol for FES-induced standing in paraplegia using percutaneous intramuscular electrodes. IEEE Trans Rehabil Eng. 1995;3(4):360-66. http://dx.doi.org/10.1109/86.481976

37. Hoffer JA, Baru M, Benard S, Calderon E, Desmoulin G, Dhawan P. Initial results with fully implanted Neurostep FES system for foot drop. Proceedings of the 10th Annual Conference of the International Functional Electrical Stimulation Society; 2005; Montreal, Canada. p. 53-55.

38. Taylor PN, Burridge JH, Dunkerley AL, Wood DE, Norton JA, Singleton C, Swain ID. Clinical use of the Odstock dropped foot stimulator: its effect on the speed and effort of walking. Arch Phys Med Rehabil. 1999;80(12):1577-83. [PMID:10597809] http://dx.doi.org/10.1016/S0003-9993(99)90333-7

39. Thrasher TA, Popovic MR. Functional electrical stimulation of walking: function, exercise and rehabilitation. Ann Readapt Med Phys. 2008;51(6):452-60. [PMID:18602712] http://dx.doi.org/10.1016/j.annrmp.2008.05.006

40. Lam T, Wolfe DL, Eng JJ, Domingo A. Lower limb rehabilitation following spinal cord injury. In: Eng JJ, Teasell RW, Miller WC, Wolfe DL, Townson AF, Hsieh JTC, Connolly SJ, Mehta S, Sakakibara BM, editors. Spinal cord injury rehabilitation evidence. Vancouver (Canada): ICORD; 2010. p. $1-47$.

41. Sykes L, Ross ER, Powell ES, Edwards J. Objective measurement of use of the reciprocating gait orthosis (RGO) and the electrically augmented RGO in adult patients with spinal cord lesions. Prosthet Orthot Int. 1996;20(3):18290.

\section{[PMID:8985998]}

42. Ferguson KA, Polando G, Kobetic R, Triolo RJ, Marsolais EB. Walking with a hybrid orthosis system. Spinal Cord. 1999;37(11):800-804. [PMID:10578252] http://dx.doi.org/10.1038/sj.sc.3100922

43. Merati G, Sarchi P, Ferrarin M, Pedotti A, Veicsteinas A. Paraplegic adaptation to assisted-walking: energy expenditure during wheelchair versus orthosis use. Spinal Cord. 2000;38(1):37-44. [PMID:10762196] http://dx.doi.org/10.1038/sj.sc.3100946

44. Nene AV, Patrick JH. Energy cost of paraplegic locomotion using the ParaWalker-electrical stimulation "hybrid" orthosis. Arch Phys Med Rehabil. 1990;71(2):116-20. [PMID:2302043]

45. Nightingale EJ, Raymond J, Middleton JW, Crosbie J, Davis GM. Benefits of FES gait in a spinal cord injured population. Spinal Cord. 2007;45(10):646-57.

[PMID:17646840]

http://dx.doi.org/10.1038/sj.sc.3102101
46. Creasey GH, Ho CH, Triolo RJ, Gater DR, DiMarco AF, Bogie KM, Keith MW. Clinical applications of electrical stimulation after spinal cord injury. J Spinal Cord Med. 2004;27(4):365-75. [PMID:15484667]

47. Graupe D, Cerrel-Bazo H, Kern H, Carraro U. Walking performance, medical outcomes and patient training in FES of innervated muscles for ambulation by thoracic-level complete paraplegics. Neurol Res. 2008;30(2):123-30.

[PMID:18397602]

http://dx.doi.org/10.1179/174313208X281136

48. Thrasher TA, Flett HM, Popovic MR. Gait training regimen for incomplete spinal cord injury using functional electrical stimulation. Spinal Cord. 2006;44(6):357-61. [PMID:16249784] http://dx.doi.org/10.1038/sj.sc.3101864

49. Tomovic R. Hybrid actuators for orthotic systems: hybrid assistive systems. Advances in External Control of Human Extremities: Proceedings of 4th International Symposium on External Control of Human Extremities; 1972 Aug 28-Sep 2; Dubrovnik, Croatia; Dubrovnik (Croatia): Yugoslav Comittee for Electronics and Automation; 1973. p. 73.

50. Popovic D, Tomovi R, Schwirtlich L. Hybrid assistive system-the motor neuroprosthesis. IEEE Trans Biomed Eng. 1989;36(7):729-37. [PMID:2787281]

http://dx.doi.org/10.1109/10.32105

51. Durfee WK, Hausdorff JM. Regulating knee joint position by combining electrical stimulation with a controllable friction brake. Ann Biomed Eng. 1990;18(6):575-96. [PMID:2281882] http://dx.doi.org/10.1007/BF02368449

52. Solomonow M, Baratta R, Hirokawa S, Rightor N, Walker W, Beaudette P, Shoji H, D'Ambrosia R. The RGO Generation II: muscle stimulation powered orthosis as a practical walking system for thoracic paraplegics. Orthopedics. 1989; 12(10):1309-15. [PMID:2798239]

53. Marsolais EB, Kobetic R, Polando G, Ferguson K, Tashman S, Gaudio R, Nandurkar S, Lehneis HR. The Case Western Reserve University hybrid gait orthosis. J Spinal Cord Med. 2000;23(2):100-108. [PMID:10914350]

54. Kobetic R, Marsolais EB, Triolo RJ, Davy DT, Gaudio R, Tashman S. Development of a hybrid gait orthosis: a case report. J Spinal Cord Med. 2003;26(3):254-58. [PMID:14997968]

55. To CS, Kobetic R, Schnellenberger JR, Audu ML, Triolo RJ. Design of a variable constraint hip mechanism for a hybrid neuroprosthesis to restore gait after spinal cord injury. IEEE/ ASME Trans Mechatron. 2008;13(2):197-205. http://dx.doi.org/10.1109/TMECH.2008.918551

56. Kobetic R, To CS, Schnellenberger JR, Audu ML, Bulea TC, Gaudio R, Pinault G, Tashman S, Triolo RJ. Development of hybrid orthosis for standing, walking, and stair climbing after spinal cord injury. J Rehabil Res Dev. 2009; 
46(3):447-62. [PMID:19675995]

http://dx.doi.org/10.1682/JRRD.2008.07.0087

57. To CS, Kobetic R, Triolo RJ. Hybrid orthosis system with a variable hip coupling mechanism. Conf Proc IEEE Eng Med Biol Soc. 2006;1:2928-31. [PMID:17946991]

58. Audu ML, To CS, Kobetic R, Triolo RJ. Gait evaluation of a novel hip constraint orthosis with implication for walking in paraplegia. IEEE Trans Neural Syst Rehabil Eng. 2010; 18(6):610-18. [PMID:20378478]

59. Durfee WK, Goldfarb M. Design of a controlled-brake orthosis for regulating FES-aided gait. Proceedings of the Annual International Conference of the IEEE Engineering in Medicine and Biology Society, vol. 14; 1992 Oct 29-Nov 1; Paris, France. Piscataway (NJ): IEEE; 1992. p. 1337-8.

60. Goldfarb M, Durfee WK. Design of a controlled-brake orthosis for FES-aided gait. IEEE Trans Rehabil Eng. 1996; 4(1):13-24. [PMID:8798068] http://dx.doi.org/10.1109/86.486053

61. Goldfarb M, Korkowski K, Harrold B, Durfee W. Preliminary evaluation of a controlled-brake orthosis for FESaided gait. IEEE Trans Neural Syst Rehabil Eng. 2003; 11(3):241-48. [PMID:14518787]

http://dx.doi.org/10.1109/TNSRE.2003.816873

62. Gharooni S, Tokhi MO, Heller B. The use of elastic element in a hybrid orthosis for swing phase generation in orthotic gait. Proceedings of the Annual Conference of the International Functional Electrical Stimulation Society; 2000; Aalborg, Denmark. 2000.

63. Gharooni S, Heller B, Tokhi MO. A new hybrid spring brake orthosis for controlling hip and knee flexion in the swing phase. IEEE Trans Neural Syst Rehabil Eng. 2001; 9(1):106-107. [PMID:11482357] http://dx.doi.org/10.1109/7333.918283

64. Jailani R, Tokhi MO, Gharooni S. Hybrid orthosis: the technology for spinal cord injury. J Appl Sci. 2010;10(22): 2785-2792. http://dx.doi.org/10.3923/jas.2010.2785.2792

65. Farris RJ, Quintero HA, Withrow TJ, Goldfarb M. Design of a joint-coupled orthosis for FES-aided gait. 2009 IEEE 11th International Conference on Rehabilitation Robotics; 2009 Jun 23-26; Kyoto, Japan. Piscataway (NJ): IEEE; 2009. p. 246-52.

66. Farris RJ, Quintero HA, Withrow TJ, Goldfarb M. Design and simulation of a joint-coupled orthosis for regulating FES-aided gait. 2009 IEEE 11th International Conference on Rehabilitation Robotics; 2009 Jun 23-26; Kyoto, Japan. Piscataway (NJ): IEEE; 2009. p. 1916-22.

67. Durfee WK, Rivard A. Design and simulation of a pneumatic, stored-energy, hybrid orthosis for gait restoration. J Biomech Eng. 2005;127(6):1014-19. [PMID:16438242] http://dx.doi.org/10.1115/1.2050652

68. Kangude A, Burgstahler B, Kakastys J, Durfee W. Single channel hybrid FES gait system using an energy storing orthosis: Preliminary design. Conf Proc IEEE Eng Med Biol Soc. 2009;2009:6798-6801.

69. Kangude BD, Burgstahler B, Durfee W. Engineering evaluation of the energy-storing orthosis FES gait system. Conf Proc IEEE Eng Med Biol Soc. 2010;2010:5927-30.

70. Tomovic R, Popoviv D, Gracanin F. Advances in external control of human extremities: Proceedings of the Sixth International Symposium on External Control of Human Extremities.1978 Aug 28-Sep 1; Dubrovnik, Croatia; Dubrovnik (Croatia): Yugoslav Committee for Electronics and Automation; 1978. p. 231-38.

71. Obinata G, Fukada S, Matsunaga T, Iwami T, Shimada Y, Miyawaki K, Hase K, Nakayama A. Hybrid control of powered orthosis and functional neuromuscular stimulation for restoring gait. Conf Proc IEEE Eng Med Biol Soc. 2007; 2007:4879-82. [PMID:18003099]

72. Stauffer Y, Allemand Y, Bouri M, Fournier J, Clavel R, Metrailler P, Brodard R, Reynard F. The WalkTrainer-a new generation of walking reeducation device combining orthoses and muscle stimulation. IEEE Trans Neural Syst Rehabil Eng. 2009;17(1):38-45. [PMID:19211322] http://dx.doi.org/10.1109/TNSRE.2008.2008288

73. Schmitt C, Metrailler P, Al-Khodairy A, Brodard R, Fournier J, Bouri M, Clavel R. A study of a knee extension controlled by a closed loop functional electrical stimulation. Proceedings of the Annual Conference of the International Functional Electrical Stimulation Society; 2004 Sep 6-9; Bournemouth, UK. 2004.

74. Metrailler P, Blanchard V, Perrin I, Brodard R, Frischknecht R, Schmitt C, Fournier J, Bouri M, Clavel R. Improvement of rehabilitation possibilities with the MotionMaker TM. Proceedings of the First IEEE/RAS-EMBS International Conference on Biomedical Robotics and Biomechatronics; 2006 Feb 20-22; Pisa, Italy. Piscataway (NJ): IEEE; 2006. p. 359-64.

75. Metrailler P, Brodard R, Clavel R, Frischknecht R. Closed loop electrical muscle stimulation in spinal cord injured rehabilitation. Proceedings of the Mediterranean Forum of Physical and Rehabilitation Medicine; 2006 Oct 18-21; Villamura, Portugal; Lausanne (Switzerland): Infoscience, EPFL; 2006.

76. Bouri M, Gall ML, Clavel R. A new concept of parallel robot for rehabilitation and fitness: The Lambda. Proceedings of the IEEE International Conference on Biomedical Robotics and Biomimetics; 2009 Dec 19-23; Guilin, China; Piscataway (NJ): IEEE; 2009. p. 2503-8.

77. Obinata G, Ogisu T, Hase K, Kim Y, Genda E. State estimation of walking phase and functional electrical stimulation by wearable device. Conf Proc IEEE Eng Med Bio Soc. 2009;2009:5901-4.

78. Vallery H, Stützle T, Buss M, Abel D. Control of a hybrid motor prosthesis for the knee joint. Proceedings of the International Federation of Automatic Control World Con- 
gress; 2005 Jul 4-8; Prague, Czech Republic; Laxenburg (Austria): IFAC-PapersOnLine; 2005.

79. Vallery H, Buss M. Towards a hybrid motor neural prosthesis for gait rehabilitation: a project description. J Autom Control. 2005;15:19-22.

80. Schmitt C, Metrailler P, Al-Khodairy A, Brodard R, Fournier J, Bouri M, Clavel R. The MotionMaker: a rehabilitation system combining an orthosis with closed loop electrical muscle stimulation. Proceedings of the 8th Vienna International Workshop on Functional Electrical Stimulation; 2004 Sep 10-13; Vienna, Austria; 2004. p. 117-20.

81. Fukada S, Obinata G, Hase K, Nakayama A, Shimada Y, Matsunaga T, et al. Development of a hybrid power assist orthosis with FES. 11th Annual Conference of the International Functional Electrical Stimulation Society; 2006 Sep 12-15; Sendai, Japan.

82. Koutsou AD, Moreno JC, Pons JL, Gallego JA, Rocon E. Muscle selectivity for superfial matrix electrodes. International Symposium Computer Methods in Biomechanics and Biomedical Engineering; 2010 Feb 24-27; Valencia, Spain.

83. Dietz V. Spinal cord pattern generators for locomotion. Clin Neurophysiol. 2003;114(8):1379-89. [PMID:12888019] http://dx.doi.org/10.1016/S1388-2457(03)00120-2

84. Zimmerli L, Duschau-Wicke A, Riener R, Mayr A, Lunenburger L. Virtual reality and gait rehabilitation: Augmented feedback for the Lokomat. Proceedings of the Virtual Rehabilitation International Conference; 2009 Jun 29-Jul 2; Haifa, Israel; Piscataway (NJ): IEEE; 2009. p. 150-3.

85. Riener R, Lünenburger L, Jezernik S, Anderschitz M, Colombo G, Dietz V. Patient-cooperative strategies for robot- aided treadmill training: first experimental results. IEEE Trans Neural Syst Rehabil Eng. 2005;13(3):380-94. [PMID:16200761] http://dx.doi.org/10.1109/TNSRE.2005.848628

86. Jackson AB, Carnel CT, Ditunno JF, Read MS, Boninger ML, Schmeler MR, Williams SR, Donovan WH; Gait and Ambulation Subcommittee. Outcome measures for gait and ambulation in the spinal cord injury population. J Spinal Cord Med. 2008;31(5):487-99. [PMID:19086706]

87. Ditunno J, Scivoletto G. Clinical relevance of gait research applied to clinical trials in spinal cord injury. Brain Res Bull. 2009;78(1):35-42. [PMID:18848865]

http://dx.doi.org/10.1016/j.brainresbull.2008.09.003

Submitted for publication March 15, 2011. Accepted in revised form October 4, 2011.

This article and any supplementary material should be cited as follows:

del-Ama AJ, Koutsou AD, Moreno JC, de-los-Reyes A, Gil-Agudo A, Pons JL. Review of hybrid exoskeletons to restore gait following spinal cord injury. J Rehabil Res Dev. 2012;49(4):497-514.

http://dx.doi.org/10.1682/JRRD.2011.03.0043

AL SURMISSIONS SCREENED BY $\checkmark$ iThenticate:

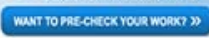

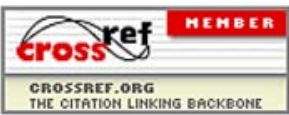

